\title{
Evaluation of gamma-ray and neutron shielding features of heavy metals doped $\mathrm{Bi}_{2} \mathrm{O}_{3}-\mathrm{BaO}-\mathrm{Na}_{2} \mathrm{O}-\mathrm{MgO}-\mathrm{B}_{2} \mathrm{O}_{3}$ glass systems
}

\author{
M.I. Sayyed ${ }^{\mathrm{a}, *}$, Ashok Kumar ${ }^{\mathrm{b}, \mathrm{c}}$, H.O. Tekin ${ }^{\mathrm{d}, \mathrm{e}}$, Ramandeep Kaur ${ }^{\mathrm{c}}$, Mandeep Singh ${ }^{\mathrm{f}}$, O. Agar ${ }^{g}$, \\ Mayeen Uddin Khandaker ${ }^{\mathrm{h}}$ \\ ${ }^{a}$ Department of Physics, Faculty of Science, University of Tabuk, Tabuk, Saudi Arabia \\ ${ }^{\mathrm{b}}$ University College, Benra- Dhuri, Punjab, India \\ ${ }^{\mathrm{c}}$ Department of Physics, Punjabi University, Patiala, Punjab, India \\ ${ }^{\mathrm{d}}$ Uskudar University, Vocational School of Health Services, Radiotherapy Department, Istanbul 34672, Turkey

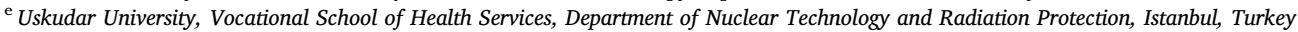 \\ ${ }^{\mathrm{f}}$ CSIR-National Physical Laboratory, Dr. K.S. Krishnan Marg, New Delhi 110012, India \\ ${ }^{\mathrm{g}}$ Karamanoğlu Mehmetbey University, Department of Physics, Karaman, Turkey \\ ${ }^{\text {h }}$ Centre for Biomedical Physics, School of Healthcare and Medical Sciences, Sunway University, 47500 Bandar Sunway, Selangor Darul Ehsan, Malaysia
}

\section{A R T I C L E I N F O}

\section{Keywords:}

Borate glasses

Melt-quenching method

FTIR

Gamma photon

MCNPX

Shielding

\begin{abstract}
A B S T R A C T
Recognizing the vast uses of radioactive sources in several sectors such as industry, medicine, agriculture, development of effective radiation shielding material finds great significance. Present work is aimed to explore potential glass based material for neutron and gamma ray shielding applications. In the present study, several borate glasses with composition of $(20+\mathrm{x}) \mathrm{Bi}_{2} \mathrm{O}_{3}-20 \mathrm{BaO}-10 \mathrm{Na}_{2} \mathrm{O}-10 \mathrm{MgO}-(40-\mathrm{x}) \mathrm{B}_{2} \mathrm{O}_{3}$ (where $\mathrm{x}=0,5,10,15$ and $20 \mathrm{~mol} \%$ ) were successfully synthesized via melt-quenching method, and evaluated their gamma-ray and neutron shielding features. The densities of the studied glasses are increased with the addition of $\mathrm{Bi}_{2} \mathrm{O}_{3}$ content. The non-existence of any sharp peak in X-ray diffraction spectra confirms the amorphous nature of the glasses. Fourier transform infrared spectroscopy gives the necessary information regarding the structure of the glasses. The optical band gap for both direct and indirect transitions decreases from 2.905 to $2.806 \mathrm{eV}$ and 2.661 to $2.536 \mathrm{eV}$ as $\mathrm{B}_{2} \mathrm{O}_{3}$ replaced with $\mathrm{Bi}_{2} \mathrm{O}_{3}$. Some quantities namely mass attenuation coefficients $(\mu / \rho)$, half-value layer (HVL), mean free path (MFP), macroscopic effective removal cross sections $\left(\Sigma_{\mathrm{R}}\right)$ and transmission factor (TF) have been studied theoretically and computationally for gamma-ray and neutron shielding characteristics. The correlation coefficient $\left(\mathrm{R}^{2}\right)$ values between the XCOM and MCNPX results of all the glasses were found to be almost 1 . According to our results, Bi40B20 sample with the highest amount of $\mathrm{Bi}_{2} \mathrm{O}_{3}$ has the lowest MFP and TF values, and this suggested that the gamma and neutron shielding performances of the $\mathrm{Bi}_{2} \mathrm{O}_{3}-\mathrm{BaO}-\mathrm{Na}{ }_{2} \mathrm{O}-\mathrm{MgO}$ $\mathrm{B}_{2} \mathrm{O}_{3}$ glasses are improved with the addition of $\mathrm{Bi}_{2} \mathrm{O}_{3}$ content.
\end{abstract}

\section{Introduction}

Recognizing the importance of effective shielding of human and environmental health from the indirect (e.g. leaked, scattered) or direct exposure of ionizing radiations, the development of composite materials have gained a great attention to the scientific community (Saeed et al., 2014). An ideal shielding material should have high absorption cross-section for radiation and, at the same time, irradiation effects on its mechanical and optical properties should be small. The use of traditional materials namely lead $(\mathrm{Pb})$, concrete, lead glass etc. is best known for gamma radiation shielding because of their high density and atomic number but they are suffering a number of drawbacks including their high cost, $\mathrm{Pb}$ toxicity to human and his environment, etc. (Kaur et al., 2015; M.I. Sayyed et al., 2018b). Since, as a base material, glass possesses some advantageous properties such as high refractive index, high optical transparency to visible light and effective absorption crosssections for X-ray/gamma photons, low cost, etc. towards ionizing radiation shielding (Khanna et al., 1996; Kirdsiri et al., 2011). Thus, commercial lead-free glass based on other heavy elements such as barium and bismuth may offer comparable features for gamma radiation shielding. Considering the suitable physico-chemical properties of glass, considerable attention has been paid by the scientific community to develop a better glass systems to be used as radiation detectors (Alnins et al., 2016), lasers (Campbell and Suratwala, 2000), optical

\footnotetext{
* Corresponding author.

E-mail address: mabualssayed@ut.edu.sa (M.I. Sayyed).
} 